Original

\title{
Lack of Inhibition of BBN-induced Bladder Carcinogenesis in C57BL/6 Mice by Intravesical Instillation of KRN 7000
}

\author{
Makoto Mitsuhashi ${ }^{1}$, Hideki Wanibuchi ${ }^{1}$, Min Wei $^{1}$, Ken'ichiro Doi ${ }^{1}$, \\ Keiichirou Morimura ${ }^{1}$, Chikayoshi Masuda ${ }^{2}$, Seiji Wada², Tatsuya Nakatani², \\ Tadao Kakizoe ${ }^{3}$, and Shoji Fukushima ${ }^{1}$ \\ ${ }^{1}$ Department of Pathology, Osaka City University Medical School, 1-4-3 Asahi-machi, Abeno-ku, Osaka 545-8585, \\ Japan \\ ${ }^{2}$ Department of Urology, Osaka City University Medical School, 1-4-3 Asahi-machi, Abeno-ku, Osaka, 545-8585, Japan \\ ${ }^{3}$ National Cancer Center, Tsukiji 5-1-1, Chuoh-ku, Tokyo 104-0045, Japan
}

\begin{abstract}
The immunostimulatory $\alpha$-galactosylceramide, KRN 7000 or (2S, 3S, 4R)-1-0-( $\alpha$-D-galactopyranosyl)-2-(Nhexacosnoylamino)-1,3,4-octadecatrienol, might be anticipated to have antitumor activity in vivo apart from any direct toxicity to cancer cells. We investigated inhibition of mouse bladder carcinogenesis by intravesically instillated KRN 7000. C57BL/6 mice were divided into 4 groups; all first receiving the carcinogen $0.05 \%$ N-butyl-N-(4hydroxybutyl)nitrosamine in drinking water for 8 weeks. Next, groups 1 and 2, respectively were administered 10 and $0.1 \mu \mathrm{g} / \mathrm{kg}$ of KRN 7000 intravesically once weekly for 17 weeks. Group 3 received only $0.3 \mathrm{ml}$ of saline (vehicle control). Group 4 did not undergo bladder catheterization. By histologic examination at 26 weeks, the incidence of bladder carcinoma of all types tended to be higher in group 1 than in group 3, but without significance. The incidence of bladder carcinoma in group 4, (no catheterization), was similar to that in group 1. Only one precancerous lesion (papillary or nodular dysplasia) was seen in each of groups 3 and 4. Thus vesical instillation of KRN 7000 did not inhibit bladder carcinogenesis in mice, exposed to the carcinogen studied. (J Toxicol Pathol 2003; 16: 19-23)
\end{abstract}

Key words: KRN 7000, C57BL/6 mouse, intravesical instillation therapy, bladder carcinoma

\section{Introduction}

Patients with urinary bladder cancer have a high risk of recurrence after transurethral resection ${ }^{1}$. Further, a tumor in recurrence is often biologically more aggressive than initially ${ }^{1}$. Although the mechanism underlying this high risk of recurrence have not been well explained, two hypotheses have been proposed. One is that cancer cells might be transplanted into urothelium at another site through the urinary stream. Urothelial trauma during endoscopy may provide an opportune site for such tumor cells to implant and grow. Laboratory studies in animals and circumstantial evidence in patients have provided evidence supporting this mechanism for some recurrences ${ }^{1,2}$. Soloway et al. ${ }^{3}$ reported high susceptibility of cauterized urinary bladder to tumor cell implantation in a mouse model. In contrast, Nakamura et al. ${ }^{4}$ suggested the presence of a system in intact

Received: 21 September 2002, Accepted: 20 December 2002 Mailing address: Makoto Mitsuhashi, Department of Pathology, Osaka City University Medical School, 1-4-3 Asahi-machi, Abeno-ku, Osaka 545-8585, Japan

TEL: 81-06-6645-3736 or 3737 FAX: 81-06-6646-3093

E-mail: mitsuhashi@med.osaka-cu.ac.jp urothelium, especially involving umbrella cells, that works to prevent implantation. The other hypothesis is one of urothelial multifocal carcinogenesis. Some reports describing histologic mapping of bladders resected for invasive cancer have documented additional findings of multifocal carcinoma or carcinoma in situ (CIS) in approximately $80 \%$ of specimens ${ }^{1,5}$. Other reports based on biopsy specimens showed an incidence of atypia, CIS, or cancer from normal-appearing mucosa at distant sites from an evident tumor, ranged between $20 \%$ and $80 \%^{1}$. Various anticancer agents have been instilled into the urinary bladder to treat such high-risk epithelia. Intravesical instillation therapy with bacillus Calmette-Guerin (BCG) has been used for more than 20 years to treat multifocal CIS and also as an adjuvant therapy after transurethral resection of Ta (noninvasive papillary carcinoma) and $\mathrm{T} 1$ (subepithelial connective tissue invasion tumor) papillary bladder cancer, this is now considered the most successful immunotherapy for bladder tumors. Sometimes, however, the therapeutic protocol cannot be completed because of serious side effects,

Abbreviations: BBN: N-butyl-N-(4-hydroxybutyl)nitrosamine, DC: dendritic cell, NK: natural killer, NKT: natural killer T, BCG: bacillus Calmette-Guerin, CIS: carcinoma in situ. 
such as, pyrexia, generalized fatigue, and bladder pain. Recently developed agents with less potential for side effects are hoped to be effective for intravesical immunotherapy.

The immunostimulatory $\alpha$-galactosylceramide, KRN 7000 or $(2 \mathrm{~S}, 3 \mathrm{~S}, 4 \mathrm{R})-1-\mathrm{O}-(\alpha$-D-galactopyranosyl)-2-(Nhexacosnoylamino)-1,3,4-octadecatrienol $\left(\mathrm{C}_{50} \mathrm{H}_{99} \mathrm{NO}_{9}\right.$ : $\mathrm{MW}$. 858.33; Fig. 1) might be anticipated to have antitumor activity in vivo apart from any direct toxicity to cancer cells ${ }^{6}$, and there are many proofs in the literature about its antitumor effects in mice. We investigated inhibition of mouse bladder carcinogenesis by intravesically instillated KRN 7000 .

\section{Materials and Methods}

\section{Experimental animals}

Female C57BL/6 mice, 5 weeks old and weighing about $25 \mathrm{~g}$, were purchased from Charles River Japan, Inc. (Kanagawa, Japan). The animals were housed in plastic cages with a bedding of paper chips, five mice per cage, in an environmentally controlled room maintained at a temperature of $22 \pm 2^{\circ} \mathrm{C}$, a relative humidity of $55 \pm 10 \%$, and a $12 \mathrm{~h} / 12 \mathrm{~h}$ light-dark cycle. Standards diet (Oriental MF; Oriental Yeast, Co. Tokyo, Japan) and water were available ad libitum throughout the experiment.

\section{Chemicals}

$\mathrm{N}$-butyl-N-(4-hydroxybutyl) nitrosamine (BBN) was obtained from Tokyo Kasei (Tokyo, Japan). KRN 7000 was kindly provided by KIRIN Brewery (Tokyo, Japan).

\section{Experimental design}

At 6 weeks of age, the mice were divided into four groups as specified below (Fig. 2) and all mice were given $0.05 \% \mathrm{BBN}$ in the drinking water for 8 weeks to initiate bladder carcinogenesis. One week later after the initiation period, groups 1 and 2 (15 mice each) respectively were administered 10 or $0.1 \mu \mathrm{g} / \mathrm{kg}$ of KRN 7000 once weekly for 17 weeks in $0.1 \mathrm{ml}$ of saline, given by intravesical instillation under anesthesia with intraperitoneal pentobarbital (Nembutal, ABBOTT Laboratories, Illinois, USA). As a catheter for intravesical instillation, we used the sheath of an intravenous injection catheter, inserting it through the urethra into the urinary bladder, after expulsion of the urine in the bladder, KRN 7000 was instilled using a 1 $\mathrm{ml}$ syringe pump. About $2 \mathrm{~h}$ after injection, the agent was allowed to drain from the bladder through the catheter. Group 3 (15 mice) received $0.1 \mathrm{ml}$ of saline intravesically as a control. Group 4 (10 mice) underwent no catheterization or anesthesia.

During the experiment, the health of mice was checked daily. The mice were weighed every 2 weeks during the initiation period and then before each intravesical instillation. Water consumption and food intake were recorded every 4 weeks over a period of 2 days. The experiment was terminated at 26 weeks after it began, 1

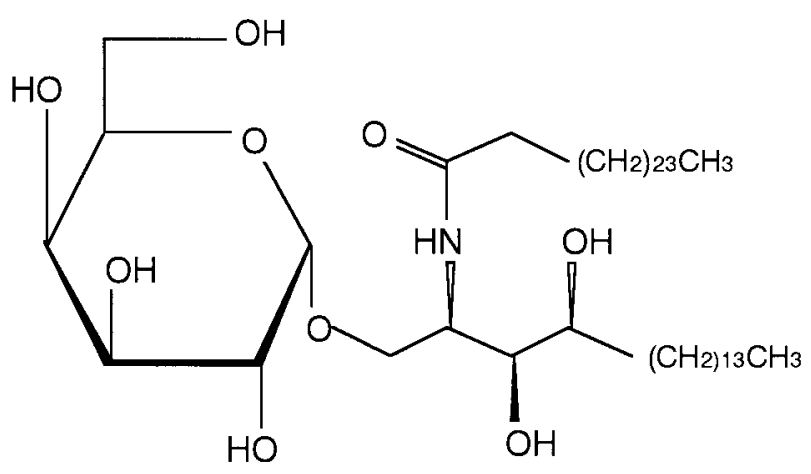

KRN $7000\left(\alpha\right.$-galactosylceramide; $\left.\mathrm{C}_{50} \mathrm{H}_{99} \mathrm{NO} 9, \mathrm{MW}=858.34\right)$

Fig. 1. Chemical structure of KRN 7000.

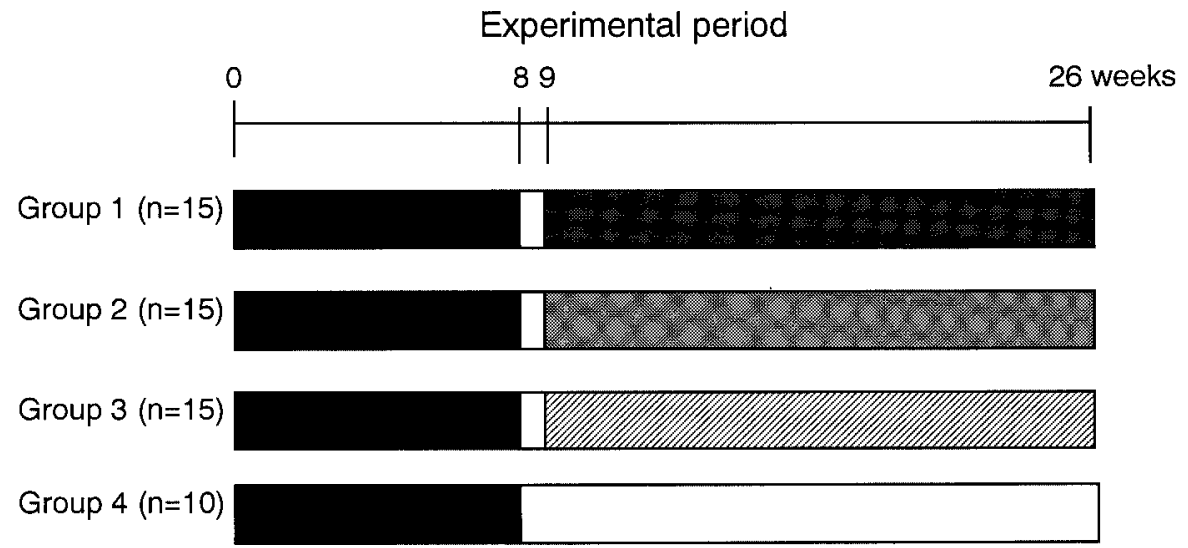

Fig. 2. Experimental protocol for our study, 6-week-old female C57BL/6 mice. Black, $0.05 \%$ BBN in drinking water for first 8 weeks. Dark gray, $10 \mu \mathrm{g} / \mathrm{kg} \mathrm{KRN} 7000$ by intravesical instillation once weekly for 17 times. Light gray, $0.1 \mu \mathrm{g} / \mathrm{kg} \mathrm{KRN} 7000$ by intravesical instillation once weekly for 17 times. Crosshatched saline by intravesical instillation once weekly for 17 times. 
week after the last instillation. Surviving mice were killed under light ether anesthesia. The urinary bladder was inflated with $10 \%$ buffered formalin as a solution fixative and then removed. The bladder was then weighed. The entire bladder was cut longitudinally into multiple strips according to the number and size of macroscopic tumors. These tissues were embedded in paraffin and examined histopathologically. Sections were cut and stained with hematoxylin and eosin ( $\mathrm{H}$ and $\mathrm{E}$ ) for microscopic examination. Liver, kidney, and spleen were also removed, weighed, examined macroscopically, and stained with $\mathrm{H}$ and E for histopathologic assessment. Mice in a critical condition were sacrificed and examined similarly at an earlier period.

\section{Statistical analysis}

Fisher's exact probability test was used to analyze the incidence of bladder tumors, and Student's t test was used for testing differences in body weights and relative organ weights between the groups. A value of p less than 0.05 was considered to indicate significance.

\section{Results}

By the middle of the experiment, eight mice died of overdoses of pentobarbital anesthesia as a complication of instillation treatment.

Body weight, food consumption, water intake, and organ weight

Body weights were similar in all groups during the initiation period, but after commencement of instillation treatment, body weight gains were less in groups 1 to 3 than in group 4. Body weights were similar between groups 1 to 3 throughout the instillation period (Table 1).

No remarkable differences in the water intake or food consumption were noted between groups 1 to 3 during the experiment. Mice in group 4 consumed more food and water than others during the instillation period (Table 1).

Mean weights of liver and kidney (Table 1), as well as spleen (data not shown), were similar between all groups. Mean urinary bladder weights were similar in groups 1 to 4 (Table 1).

\section{Macroscopic findings}

Bladder tumors were evident macroscopically in 5 of 11 mice in group $1(45.5 \%) ; 2$ of 13 in group $2(15.4 \%) ; 2$ of 13 in group 3 (15.4\%); and 3 of 13 in group 4 (25.1\%). Almost all tumors were solitary, and they were examined histopathologically. No significant macroscopic findings were noted in liver or kidney.

\section{Histopathological findings}

Histopathologic changes of urinary bladder epithelium were classified as showing either preneoplastic change specifically, papillary or nodular (PN) dysplasia, (7-9) or carcinoma (transitional cell or squamous cell). No other bladder neoplasm occurred in these experiments. Data are summarized in Table 2. Total incidence of bladder carcinoma tended to be higher in group 1 than group 3 , but the differences were not significant. The total incidence of bladder carcinoma in group 4 was similar to that in group 1 . PN dysplasia was seen only twice, one in each of groups 3 and 4. No specific histopathologic changes were seen in liver or kidney between KRN 7000-treated and controls groups.

Table 1. Final Body Weight, Food Consumption, Water Intake, and Liver and Kidney Weight in Mice

\begin{tabular}{|c|c|c|c|c|c|c|c|c|c|}
\hline & Group & o BBN intravesical instillatic & $\begin{array}{l}\text { No. of mice } \\
\text { examined }\end{array}$ & $\begin{array}{c}\text { Body weight }(\mathrm{g}) \\
\text { at week } 26\end{array}$ & $\begin{array}{l}\text { Urinary bladder } \\
\text { weight }(\mathrm{g})\end{array}$ & $\begin{array}{c}\text { Liver } \\
\text { weight }(\mathrm{g})\end{array}$ & $\begin{array}{c}\text { Kidney } \\
\text { weight }(\mathrm{g})\end{array}$ & $\begin{array}{l}\text { Food consumption } \\
\text { (week 26) } \\
\text { (g/mouse/day) } \\
\text { (mean) }\end{array}$ & $\begin{array}{c}\text { n Water intake } \\
\text { (week 26) } \\
\text { (ml/mouse/day) } \\
\text { (mean) }\end{array}$ \\
\hline 1 & + & $10 \mu \mathrm{g} / \mathrm{kg}$ b.w KRN 7000 & 11 & $22.7 \pm 1.5^{\mathrm{a}}$ & $1.1 \pm 0.1^{\mathrm{a}}$ & $1.1 \pm 0.1^{\mathrm{a}}$ & $0.32 \pm 0.03$ & 6.0 & 6.4 \\
\hline 2 & + & $0.1 \mu \mathrm{g} / \mathrm{kg}$ b.w KRN 7000 & 13 & $22.4 \pm 1.2 *$ & $1.1 \pm 0.1$ & $1.1 \pm 0.1$ & $0.32 \pm 0.05$ & 5.6 & 6.2 \\
\hline 3 & + & $0.9 \%$ saline & 13 & $23.2 \pm 1.4^{*}$ & $1.1 \pm 0.2$ & $1.1 \pm 0.2$ & $0.31 \pm 0.04$ & 5.5 & 6.3 \\
\hline 4 & + & no treatment & 10 & $27.6 \pm 3.6$ & $1.1 \pm 0.1$ & $1.1 \pm 0.1$ & $0.30 \pm 0.03$ & 7.1 & 7.9 \\
\hline
\end{tabular}

BBN; N-butyl-N-(4-hydroxybutyl)nitrosamine, a; Values are mean $\pm \mathrm{SD}$, *; Significantly different from group 4, $\mathrm{P}<0.05$.

Table 2. Histologic Findings in Mouse Urinary Bladder

\begin{tabular}{|c|c|c|c|c|c|c|c|}
\hline \multirow[t]{2}{*}{ Group } & \multicolumn{2}{|l|}{ Treatment } & \multirow[t]{2}{*}{ No. of mice examined } & \multicolumn{3}{|c|}{ Carcinoma } & \multirow[t]{2}{*}{ PN dysplasia (\%) } \\
\hline & $0.05 \% \mathrm{BBN}$ & intravesical instillation & & TCC $(\%)$ & $\mathrm{SCC}(\%)$ & Total $(\%)$ & \\
\hline 1 & + & $10 \mu \mathrm{g} / \mathrm{kg}$ b.w KRN 7000 & 11 & $3(27.3)$ & $2(18.2)$ & $5(45.5)$ & $0(0)$ \\
\hline 2 & + & $0.1 \mu \mathrm{g} / \mathrm{kg}$ b.w KRN 7000 & 13 & $2(15.4)$ & $0(0)$ & $2(15.4)$ & $0(0)$ \\
\hline 3 & + & $0.9 \%$ saline & 13 & $1(7.7)$ & $0(0)$ & $1(7.7)$ & $1(7.7)$ \\
\hline 4 & + & no treatment & 10 & $2(16.7)$ & $2(16.7)$ & $3(25.1)$ & $1(8.3)$ \\
\hline
\end{tabular}

BBN; N-butyl-N-(4-hydroxybutyl)nitrosamine, TCC; transitional cell carcinoma, SCC; squamous cell carcinoma, PN; papillary or nodular. 


\section{Discussion}

KRN 7000 is isolated from extracts of the sponze, Agelas mauritianus $^{10}$. Kobayashi et al. reported that this agent markedly augmented natural killer (NK) activity in spleen cells in vivo, and also showed significant antitumor activity in mice with lung metastasis following transplantation of B16 melanoma cells ${ }^{11}$. Nakagawa et al. ${ }^{12}$ reported that KRN 7000 had a strong antitumor activity in mice with Colon 26 hepatic metastases, accompanied by marked activation of NK cells in the liver, and intravenous injection of KRN 7000 resulted in a high percentage of cures in their mice, which thus acquired tumor-specific immunity ${ }^{13}$. Moreover, the antitumor effect was stronger than those of known chemotherapeutic agents such as mitomycin C, 5-fluorouracil, or adriamycin; the effect was equal to that of interleukin-12. Accordingly, KRN 7000 is hoped to be useful for the treatment of various liver metastases. Reports have suggested a sequential mechanism of antitumor activity. First, the molecule of KRN 7000 is taken up by a dendritic cell (DC) and then presented on the DC membrane together with a CD1 molecule. The CD1/ KRN 7000 complex is recognized by natural killer T (NKT) cells with $\mathrm{V} \alpha 14 / \mathrm{V} \beta 8^{12}$, attacking tumor cells ${ }^{14}$ and releasing various cytokines such as interleukin- 4 and interferon- $\gamma^{12}$. In turn, NK cells and macrophages are activated and injure tumor cells non-specifically ${ }^{15}$. Furthermore, $\mathrm{CD}^{+}$cytotoxic $\mathrm{T}$ lymphocytes with a tumor-specific effect are induced. This combination of antitumor mechanisms for KRN 7000 is considered unique, differing in important ways from those of other antitumor agents. In recent studies, activation of DC by KRN 7000 in vitro, a significant antitumor effect was seen when DCs were injected into cancer- bearing mice ${ }^{6,16}$. Such treatment of various cancers using KRN 7000 has been considered promising.

As specialized leukocytes, DCs in different human organs show various degrees of maturity and sometimes have an organ-specific name ${ }^{17}$, such as Langhans cells in skin. DCs also circulate in the blood circulation, accounting for $0.14 \%$ of peripheral blood leukocytes. Although the mechanism of DC activation has not been fully elucidated, DCs apparently infiltrate cancerous tissue, take up tumor antigens, and migrate to the periphery of the cancer where they present the antigen to T lymphocytes. In tumors, DC has been often observed in association with $\mathrm{T}$ cells. According to another report, cancer cells expressing CD1d molecules become targets of NKT cells activated by KRN $7000^{18}$. Thus detection of CD1d expression by cancer cells might be an indication of a potential anticancer effect ${ }^{19}$. Little has been reported about localization of DC in the urinary bladder or its cancers, but Hart et al. ${ }^{20}$ found $\mathrm{MHC}$ class $\mathrm{II}^{+} \mathrm{DC}$ beneath the epithelial layer, as has been seen in other epithelial surfaces ${ }^{21}$. Inoue et al. ${ }^{22}$ reported that $\mathrm{S} 100$ protein-positive DC, suspected to be a prognostic factor in various cancers, were also present in transitional cell carcinomas of the urinary bladder.

Antitumor effects of intravesical BCG therapy are well known, and involve activation of the immunologic response ${ }^{23}$. Yet BCG often has serious side effects and new immunotherapeutic agents have been sought for bladder tumors. We expected that intravesical instillation of KRN 7000 would be effective against bladder cancer, as well as being essentially free of serious side effects. In mice, piloerection soon after intravenous administration and liver toxicity from KRN 7000 have been reported ${ }^{12}$, but we did not find any abnormalites in our samples of liver, spleen, or kidney, and observed no piloerection upon treatment.

In the present experiments, we planned to use an intravesical concentration of KRN 7000 that corresponded to the most effective dose in in vitro studies $(100 \mathrm{ng} / \mathrm{ml})$. We therefore used a similar dose in high-dose mice and a 1:100 dilution of this in low-dose mice. The ideal duration of drug retention in the bladder and the volume to be instilled effective are uncertain. Agents for intravesical instillation therapy in humans (pirarubicin hydrochloride or cytarabine) are usually retained for only $30 \mathrm{~min}$, and are instilled in a solution volume of $20 \mathrm{ml}$. We based duration and relative amounts on these protocols, in order to avoid missing the therapeutic effect of KRN 7000. The frequency of instillation corresponded to chemotherapy instillation protocols for the human bladder, once weekly. Intraperitoneal administration every 4 days has been reported to show a clear anticancer effect in mice, while overly frequent administration of the agent was avoided so as not to decrease cytokine induction (unpublished data).

In the present experiment, long cumulative intervals of respiratory insufficiency related to anesthesia may have caused lower body weights in catheterized mice. No significant differences in incidence of bladder carcinoma or PN dysplasia noted between groups, so KRN 7000 neither inhibited nor facilitated bladder carcinogenesis. Bladder tumor incidence in KRN 7000-instilled mice (groups 1 and 2) was higher than in saline controls (group 3), but this tendency was not significant. This minor increase could reflect mucosal injuries from catheterization rather than tumor-stimulating effects of KRN 7000; some studies of intravescal instillation therapy have suggested that catheterization itself might promote bladder carcinogenesis $^{20}$. So the total bladder carcinoma incidence in normal saline instillation group (group 3) must be higher than that of no instillation group (group 4). However, in the present experiment, that of group 3 was lower than that of group 4. Those of bladder instillation groups (groups 1 to 3 ) seemed to become higher dose dependently, but they were not significant. KRN 7000 seemed to stimulate bladder carcinogenesis, but the total bladder carcinoma incidence KRN 7000-low dose group (group 2) was rather lower than that of group 4. Variation in bladder carcinoma incidence between our groups most likely was random, and this should be originated from the failure of appropriate induction of bladder carcinogenesis by BBN treatment and/or the abscence of antitumor effect of KRN 7000 to bladder tumor. We can only say that intravesical instillation treatment with KRN 7000 did not inhibit bladder carcinogenesis in these 
mice. KRN 7000 may not have an appropriate character for intravesical instillation therapy, for example, permiability to bladder epithelium. Further investigation is necessary, however, to avoid premature generalization of this specific negative result.

In conclusion, we could not observe an inhibitory effect from intravesical instillation of KRN 7000 in C57BL/6 mice exposed to a bladder carcinogenesis.

Acknowledgements: This study was supported by a grant from the Japan Science and Technology corporation, including into the project of Core Research for Evolutional Science and Technology (CREST) in Japan and the Minisitry of Labor, Japan. We thank the pharmaceutical research laboratory at the KIRIN Brewery for generously providing KRN 7000 for our study, as well as for their valuable advice.

\section{References}

1. Wallace DMA. Superficial bladder cancer. In: Comprehensive Urology, 1st ed., BM Weiss, JRN George, and HP O'Reilly (eds), London, Edinburgh, New York, Philadelphia, St. Louis, Sydney, Toronto: Mosby, 363-372, 2001.

2. Weldon TE and Soloway MS. Susceptibility of urothelium to neoplastic cellular implantation. Urology 1975; 5: 824827.

3. Soloway MS, Nissenkorn I, and McCallum L. Urothelial susceptibility to tumor cell implantation: comparison of cauterization with N-methyl-N-nitrosourea. Urology 1983; 21: $159-161$

4. Nakamura K, Fujiyama C, Tokuda Y, Sugihara H, and Masaki Z. Bladder cancer cell implantation in recontrusted bladder in vitro: a model of tumor recurrence. BJU Int 2002; 89: $119-125$.

5. Farrow GM, Utz DC, and Rife CC. Morphological and clinical observations of patients with early bladder cancer treated with total cystectomy. Cancer Res 1976; 36: 24952501.

6. Yamaguchi Y, Ueno H, Maeda K, Kobayashi E, Inoue H, Fukushima H, and Koezuka Y. Enhansing effects of (2S, 3S, $4 \mathrm{R})$-1-O-( $\alpha$-D-galactopyranosyl)-2-(N-hexacoanoylamino)1, 3, 4-octadecanetriol (KRN 7000) on antigen-presenting function of antigen-presenting cells and anti-metastatic activity of KRN 7000 pretreated antigen presenting cells. Oncol Res 1996; 8: 399-407.

7. Ito N. Early changes caused by N-butyl-N-(4-hydroxybutyl) nitrosamine. Gann Monogr 1975; 17: 367-381.

8. Fukushima S, Murasaki G, Hirose M, Nakanishi K, Hasegawa R, and Ito N. Histopathological analysis of preneoplastic changes of during N-butyl-N-(4butylhydroxybutyl)nitrosamine-induced urinary bladder carcinogenesis in rats. Acta Pathol Jpn 1982; 32: 243-250.

9. Cohen SM, Jacobs JB, Arai M, Johansson S, and Friedell GH. Early lesions in experimental bladder cancer: Experimental design and light microscopic findings. Cancer Res 1976; 36: 2508-2511.
10. Morita M, Motoki K, Akimoto K, Natori T, Sakai T, Sawa E, Yamaji K, Koezuka Y, Kobayashi E, and Fukushima H. Structure-activity relationship of alpha-galactosylceramides against B16-bearing mice. J Med Chem 1995; 38: 21762187.

11. Kobayashi E, Motoki K, Uchida T, Fukushima H, and Koezuka Y. KRN7000, a novel immunomodulator, and its antitumor activities. Oncol Res 1995; 7: 529-534.

12. Nakagawa R, Motoki $K$, Ueno $H$, Iijima R, Nakamura $H$, Kobayashi E, Shimosaka A, and Koezuka Y. Treatment of hepatic metastasis of the Colon26 adenocarcinoma with an $\alpha$-galactosylceramide, KRN7000. Cancer Res 1998; 58: 1202-1207.

13. Ohteki $\mathrm{T}$ and MacDonald HR. Major histocompatibility complex I-related molecules control the development of CD4+ 8- and CD4-8- subsets of natural killer 1.1+T-cell receptor- $\alpha / \beta+$ cells in the liver of mice. J Exp Med 1994; 180: $690-704$.

14. Lu L, Woo J, Rao AS, Li Y, Watkins SC, Qian S, Starzl TE, Demetris AJ, and Thomson AW. Propagation of dendritic cell progenitors from normal mouse liver using GM-CSF and their maturational development in the presence of type-1 collagen. J Exp Med 1994; 179: 1823-1834.

15. Kawano T, Cui J, Koezuka Y, Toura I, Kaneko Y, Motoki K, Ueno H, Nakagawa R, Sato H, Kondo E, Koseki H, and Taniguchi M. CD1d-restricted and TCR mediated activation of V $\alpha 14$ NKT cells by glycosylceramides. Science 1997; 278: $1626-1629$.

16. Kawano T, Cui J, Koezuka Y, Toura I, Kaneko Y, Sato H, Kondo E, Harada M, Koseki H, Nakayama T, Tanaka Y, and Taniguchi M. Natural killer-like nonspecific tumor cell lysis mediated by specific ligand-activated V alpha14 NKT cells. Proc Natl Acad Sci USA 1998; 95: 5690-5693.

17. Toura I, Kawano T, Akutsu Y, Nakayama T, Ochiai T, and Taniguchi M. Cutting edge: inhibition of experimental tumor metastasis by dendritic cells pulsed with alphagalactosylceramide. J Immunol 1999; 163: 2387-2391.

18. Koezuka Y. The antitumor effects of alphagalactosylceramide. In: Dendritic Cells in Fundamental and Clinical Research,1st ed., K Inaba, M Takigawa (eds), Tokyo; Nankoudou, 137-142, 2000.

19. Spada FM, Koezuka Y, and Porceli SA. CD1d-restricted recognition of syntheticglycolipid antigens by human natural killer T cells. J Exp Med 1998; 188: 1529-1534.

20. Hart AJ and Fowler JW. Incidence of urethral stricture after transurethral resection of prostate. Effects of urinary infection, urethral flora, and catheter material and size. Urology 1981; 18: 588-591.

21. Maric I, Holt PG, Perdue MH, and Bienenstock J. Class II MHC antigen (Ia)-bearing dendritic cells in the epithelium of the rat intestine. J Immunol 1996: 156: 1408-1414.

22. Inoue K. Distribution of S-100 protein-positive dendritic cells and expression of HLA-DR antigen in transitional cell carcinoma of the urinary bladder in relation to tumour progression and prognosis. Virchows Arch A Pathol Anat 1993; 422: 351-355.

23. Brandau $\mathrm{S}$ and Bohle A. Activation of natural killer cells by bacillus Calmette Guerin. Eur Urol 2001; 39: 518-524. 